\title{
Ras-Related Protein Rab-7a
}

National Cancer Institute

\section{Source}

National Cancer Institute. Ras-Related Protein Rab-7a. NCI Thesaurus. Code C119633.

Ras-related protein Rab-7a (207 aa, $\sim 23 \mathrm{kDa}$ ) is encoded by the human RAB7A gene.

This protein is involved in many cellular processes that involve endosomes or lysosomes. 